\title{
Aktivitas Antioksidan Ekstrak Metanol Kulit Buah Ramania (Bouea macrophylla Griff) dengan Metode DPPH
}

\author{
Novita Eka Kartab Putri \\ Laboratorium Penelitian dan Pengembangan Kefarmasian "Farmaka Tropis", \\ Fakultas Farmasi, Universitas Mulawarman, Samarinda, Indonesia \\ Email:neka@farmasi.unmul.ac.id
}

\begin{abstract}
Has been conducted a research of "The Antioxidant Activity of Ramania's Rind (Bouea macrophylla Griffith) extract with DPPH method. The aim of the research is to determine antioxidant activity and value of $I_{50}$. This research used free radical inhibition 1,1diphenyl-2-picrylhydrazil (DPPH) method, that was tested to crude extract of ramania's rind. The value of $I C_{50}$ ramania's rind extract is 44,394 ppm, which is the value show hight antioxidant activity.
\end{abstract}

Keywords : (Bouea macrophylla Griffith)., Antioxidant, DPPH method, IC 50

\begin{abstract}
ABSTRAK
Telah dilakukan penelitian yang berjudul Aktivitas Antioksidan Ekstrak Kulit Buah Ramania (Bouea macrophylla Griffith) dengan metode DPPH. Penelitian ini bertujuan untuk mengetahui aktivitas antioksidan dan nilai $\mathrm{IC}_{50}$. Penelitian ini menggunakan metode peredaman radikal bebas DPPH (1,1-diphenyl-2-picrylhydrazyl) yang diujikan pada ekstrak kasar metanol kulit buah ramania (Bouea macrophylla Griffith). Nilai IC 50 yang diketahui yakni 44,394 ppm, hal tersebut menunjukan aktivitas antioksidan yang baik.
\end{abstract}

Kata Kunci: Buah Ramania (Bouea macrophylla Griffith), Antioksidan, Metode DPPH, $\mathrm{IC}_{50}$

DOI: $\underline{\text { https://doi.org/10.25026/mpc.v7i1.287 }}$

\section{PENDAHULUAN}

Aging atau penuaan pada kulit sebagian besar disebabkan oleh radiasi sinar matahari. UV A dan B dalam sinar matahari menginduksi terbentuknya Reactive Oxygen Species (ROS) dalam kulit dan mengakibatkan stress oksidatif bila jumlah ROS tersebut melebihi kemampuan pertahanan antioksidan dalam sel kulit. Perawatan utama untuk mencegah aging kulit karena stres okidatif adalah pemakaian produk pelindung matahari sedangkan untuk perawatan sekunder adalah pemakaian produk yang mengandung antioksidan (Pojsak \& Dahmane, 2011). Antioksidan dipakai untuk mencegah timbulnya penuaan kulit dan bukan gold standart 

DPPH

terapi aging kulit (Thornfeldt \& Bourne, 2010).

Antioksidan alami terdapat pada buah ramania (Bouea macrophylla Griffith) merupakan satu spesies dari suku Anacardiaceae, yang di beberapa daerah di Indonesia disebut dengan berbagai nama yang berbeda, salah satunya buah Gandaria. ). Penelitian sebelumnya oleh Lolaen dkk., (2013) menunjukkan pada jus buah gandaria memiliki aktifitas antioksidan yang diekstrasi dengan pelarut etanol $96 \%$ memiliki aktivitas antioksidan dengan menggunakan metode perendaman radikal bebas DPPH, menunjukkan IC50 sebesar 36,3 ppm. Sedangkan untuk aktivitas antioksidan pada kulit buah ramania belum diketahui.

Berdasarkan uraian di atas, dilakukan penelitian tentang uji aktivitas antioksidan untuk mengetahui besarnya aktivitas antioksidan dengan metode peredaman radikal 1,1-diphenyl-2picrylhidrazyl (DPPH) dari kulit buah ramania (Bouea macrophylla Griffith).

\section{METODE PENELITIAN}

\section{Bahan}

Bahan yang diteliti adalah kulit buah ramania (Воиea macrophylla Griffith). Proses pembuatan simplisia kulit buah ramania meliputi beberapa tahap, yakni pengumpulan kulit buah ramania, pencucian dan sortasi basah, pengeringan dan sortasi kering, serta simplisia dirajang agar proses penarikan senyawa pada saat pembuatan ekstrak daun sumpit berlangsung maksimal. Ekstraksi dilakukan dengan metode maserasi menggunakan pelarut metanol p.a.

\section{Peralatan}

Peralatan pengujian antioksidan meliputi, Spektrofotometer UV-Visible, kuvet, mikropipet, gelas kimia, pipet tetes, pipet volume, pro pipet, labu takar, vortex, batang pengaduk, spatula, tabung reaksi bertutup, corong, timbangan analitik dan botol timbang.

\section{Pengujian}

Masing-masing ekstrak dilakukan pengujian aktivitas antioksidan terhadap DPPH. Variasi konsentrasi yang digunakan untuk ekstrak metanol daun sumpit yaitu 30, 35, 40, 45, dan 50 ppm. Masing-masing konsentrasi dilakukan 3 kali pengulangan. Indikator pengujian adalah peredaman DPPH sebagai hasil absorbansi pada Spektrofotometer $U V$ Visible dengan menggunakan panjang gelombang $516 \mathrm{~nm}$.

Kapasitas antioksidan (persen inhibisi) untuk menghambat radikal bebas, dapat dihitung dengan persamaan:

$\%$ inhibisi $=\frac{\text { Abs kontrol }- \text { Abs sampel }}{\text { Abs Kontrol }} \times 100 \%$

Keterangan:

Abs Kontrol : nilai serapan (Abs) larutan control pada panjang gelombang $516 \mathrm{~nm}$

Abs Sampel : nilai serapan(Abs) larutan uji atau larutan pembanding pada panjang gelombang $514 \mathrm{~nm}$

Nilai persen inhibisi yang diperoleh kemudian dibuat kurva terhadap konsentrasi larutan uji atau pembanding $(\mu \mathrm{g} / \mathrm{ml})$. Selanjutnya dari kurva ini dibuat regresi linier sehingga diperoleh persamaan $(\mathrm{y}=\mathrm{bx}+\mathrm{a})$. Nilai IC50 sebagai parameter aktivitas antioksidan dihitung dari persamaan regresi yang diperoleh dengan memasukan nilai $50 \%$ pada y sehingga diketahui nilai konsentrasi efektifnya. Nilai IC50 larutan uji dan larutan pembanding ditentukan dari persamaan yang diperoleh dari kurva masingmasing.

\section{HASIL DAN PEMBAHASAN}

Uji aktivitas antioksidan kulit buah ramania ini dilakukan menggunakan metode perendaman radikal bebas DPPH. 

DPPH

Metode perendaman radikal bebas DPPH dipilih karena sederhana, cepat dan tidak memerlukan banyak reagen.
Hasil uji aktivitas antioksidan kulit buah ramania menggunakan konsentrasi $30,35,40,45$, dan $50 \mathrm{ppm}(\mu \mathrm{g} / \mathrm{ml})$ ditunjukkan pada tabel 1 .

Tabel 1. Nilai Absorbansi dan Persen Aktivitas Antioksidan Ekstrak Metanol Kulit Buah Ramania (Bouea macrophylla Griffith)

\begin{tabular}{|c|c|c|c|c|c|}
\hline $\begin{array}{l}\text { Konsentrasi } \\
\text { ekstrak (ppm) }\end{array}$ & Abs kontrol & Abs. Sampel & $\begin{array}{l}\% \text { Aktivitas } \\
\text { Antioksidan }\end{array}$ & $\Sigma$ & $\begin{array}{l}\mathrm{IC}_{50} \\
(\mathrm{ppm})\end{array}$ \\
\hline \multirow{3}{*}{30} & 0.55 & 0.356 & 35.27 & \multirow{3}{*}{35.33} & \multirow{15}{*}{44,394} \\
\hline & 0.55 & 0.356 & 35.27 & & \\
\hline & 0.55 & 0.355 & 35.45 & & \\
\hline \multirow{3}{*}{35} & 0.55 & 0.318 & 42.18 & \multirow{3}{*}{42.24} & \\
\hline & 0.55 & 0.318 & 42.18 & & \\
\hline & 0.55 & 0.317 & 42.36 & & \\
\hline \multirow{3}{*}{40} & 0.55 & 0.301 & 45.27 & \multirow{3}{*}{45.15} & \\
\hline & 0.55 & 0.303 & 44.91 & & \\
\hline & 0.55 & 0.301 & 45.27 & & \\
\hline \multirow{3}{*}{45} & 0.55 & 0.264 & 52.00 & \multirow{3}{*}{51.45} & \\
\hline & 0.55 & 0.267 & 51.45 & & \\
\hline & 0.55 & 0.27 & 50.91 & & \\
\hline \multirow{3}{*}{50} & 0.55 & 0.245 & 55.45 & \multirow{3}{*}{54.73} & \\
\hline & 0.55 & 0.247 & 55.09 & & \\
\hline & 0.55 & 0.255 & 53.64 & & \\
\hline
\end{tabular}

Tabel 1 menunjukkan semakin tinggi konsentrasi, maka semakin rendah absorbansinya. Hal ini dikarenakan semakin tinggi konsentrasi ekstrak, maka semakin tinggi pula kandungan zat antioksidannya, sehingga semakin banyak DPPH yang akan dihambat oleh ekstrak tersebut dan semakin sedikit DPPH yang tersisa, sehingga nilai absorbansi semakin kecil.

Berdasarkan data penelitian yang diperoleh, diketahui ekstrak metanol kulit buah ramania memiliki aktivitas antioksidan jika dilihat dari nilai $\mathrm{IC}_{50}$-nya sebesar 44,394, yang mana nilai tersebut di bawah 200 ppm. Suatu senyawa dikatakan memiliki aktivitas antioksidan yang baik apabila nilai $\mathrm{IC}_{50}$-nya kurang dari 200 ppm (Molyneux, 2004).

\section{KESIMPULAN}

Ekstrak kulit buah ramania (Bouea macrophylla Griffith) memiliki aktivitas antioksidan dengan parameter IC 50 sebesar 44,394 ppm.

\section{DAFTAR PUSTAKA}

[1] Lolaen L., Fatimawali, Citraningtyas G., 2013. Uji Aktivitas Antioksidan Kandungan Fitokimia Jus Buah Gandaria (Bouea macrophylla Griffith). Jurnal Ilmiah FarmasiUNSRAT, Vol. 2 (02).

[2] Molyneux, P. 2004. The use of the stable free radical diphenylpicrylhydrazyl (DPPH) for estimating antioxidant activity. Songklanakarin J. Sci. Technol., 2004, 26(2). 
Aktivitas Antioksidan Ekstrak Metanol Kulit Buah Ramania (Bouea macrophylla Griff) dengan Metode DPPH

[3] Poljsak, B., Dahmane, R.(2012). Free 12. Radicals and Extrinsic Skin Aging. Dermatol Research and Practice. http://dx.doi.org/10.1155/2012/135206
[4] Thornfeldt, C., Bourne, K. (2010). 16. The New Ideal in Skin Health: Separating Fact from Fiction Practical Application of the Science of Skin Care. Allured Business Media. Carol Stream, USA. 